\title{
MONITORING OF INDOOR AIR QUALITY IN CLASSROOM
}

\author{
Halima Hadziahmetovic, Nurin Zecevic \& Amina Neimarlija
}
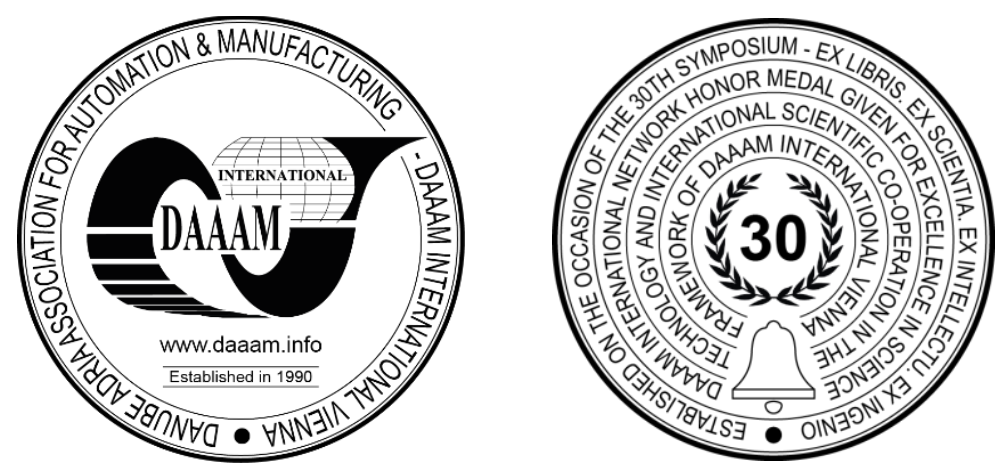

This Publication has to be referred as: Hadziahmetovic, H[alima]; Zecevic, N[urin] \& Neimarlija, A[mina] (2021). Monitoring of Indoor Air Quality in Classroom, Proceedings of the 32nd DAAAM International Symposium, pp.00400047, B. Katalinic (Ed.), Published by DAAAM International, ISBN 978-3-902734-33-4, ISSN 1726-9679, Vienna, Austria

DOI: $10.2507 / 32$ nd.daaam.proceedings.006

\begin{abstract}
Measurement of Indoor Air Quality parameters (IAQ), as $\mathrm{CO}_{2}$ concentration, temperature, and relative humidity, was performed in one classroom at the Faculty of Mechanical Engineering in Sarajevo, with the aim to assess ventilation efficiency. In 2011, several energy efficiency measurements as part of the pilot project, were implemented on the building of the Faculty of Mechanical Engineering in Sarajevo, such as thermal insulation of the building and replacement of existing boiler, but without adequate system for ventilation and cooling. Faculty still continues to use natural ventilation. With implementation of mentioned energy efficiency measures, savings on the heating energy were achieved for about $43 \%$, but at the same time due to the lack of appropriate ventilation system, there is a significant impact on indoor air quality, especially during the heating season. Beside achieved airtightness of the building, IAQ is affected by other factors, such as the volume of the room, number of users and ventilation frequency. Measurement has lasted for ten days and results were compared with the standard EN16798-1:2019. The measured values showed that in the classroom, during the winter period, the average indoor air temperature was $21{ }^{\circ} \mathrm{C}$, relative humidity $35 \%$ and measured $\mathrm{CO}_{2}$ concentrations were up to almost 3 times higher than the recommended by the standard.
\end{abstract}

Keywords: building; indoor air quality; thermal comfort; measurement; $\mathrm{CO}_{2}$ concentration.

\section{Introduction}

Buildings of educational institutions represent a significant factor in every social community, characterized by their specific role and requirements. From the aspect of energy consumption in buildings, they belong to the sector of public buildings, which is more heterogeneous when compared to residential, differing in structure, number of users and energy consumption. The importance of their role is reflected in the fact that none institution has as much influence on young people as educational institutions, where they gain their knowledge and findings, and where young people spend most of their time at the stage of life when there is rapid development of their intellectual, social and emotional capabilities [1].

High expectations of these institutions should not imply only well-educated employees and fulfillment of their primary educational objectives, but also indoor environmental quality (IEQ) has great importance for all users [1]. However, numerous studies and energy audits provide a different picture, indicating that in most cases there is an imbalance between meeting needs for energy and achieving the IEQ requirements. This is reflected in a several cases. 
One of the reasons is that many school buildings were built in the 1960s and 1970s to solve two problems: the high number of "baby boomer" children coming into the public school system, and the increasing cost of energy needed to heat or cool old school buildings. Therefore, many of the schools built during those years used "modern" energy-saving features like windows that could not be opened. While "closing the envelope" reduced the cost to heat and cool the buildings, ironically, it resulted in "sealed" classrooms that trapped poor air quality, contaminants, and drove up $\mathrm{CO}_{2}$ levels past acceptable limits [2]. On the other side, recent and emerging global standards in buildings dictate tight building envelopes, purposely limiting air infiltration with the aim to achieve energy savings and reduction of carbon footprint. These measures also have the aim to reduce inside air pollutants, which is contradictory in the situation when implementation of energy efficiency measures deteriorates health and productivity of users [3].

Unfortunately, studies have shown that many universities, classrooms, and indoor learning centers, do not have the proper ventilation rates, to begin with [2]. Most state educational institutions because of limited budget, often put the need for improvement of the facility on the second place or implement partial energy efficiency measures, which later leads to higher costs for upgrading the system. Usually it refers to the fact that most of the students still have classes in buildings where the ventilation is only ensured by natural ventilation [2].

The main causes of indoor air pollution are insufficient and inadequate ventilation frequency, emissions from cleaning products, and the chemicals emitted by building materials or furnishings [4]. Existing ventilation standards are usually minimum recommendations and optimal air quality mostly cannot be achieved in that manner, especially in the case when there is a high occupancy [5]. The most common way of expressing adequate ventilation rate is through $\mathrm{CO}_{2}$ concentration. It is directly linked to the room characteristics, the number of persons present, outdoor air quality, and ventilation rate [5]. However, a wide study of schools located in a Mediterranean area with natural ventilation system showed that the measured $\mathrm{CO}_{2}$ concentration exceeded the 1000 ppm even when the windows were open, with $\mathrm{CO}_{2}$ concentration falling below $1000 \mathrm{ppm}$ in only $28 \%$ of case studies with open windows studies [4]. In a recent study it was found that as the $\mathrm{CO}_{2}$ concentration in the classroom increases, the performance test results decrease, and it can lead to the lower attendance levels. The cause is not directly the $\mathrm{CO}_{2}$ concentration, but it can serve as an indicator of a bad IAQ which can cause more illnesses between the pupils [4]. Children are particularly sensitive to air pollution, because they inhale a large volume of air relative to their body weight and consequently the concentration of pollutants can result in a greater load on the children's body than in adults [6]. This age group is more susceptible to the influence of Sick Building Syndrome [7]. The impact of unhealthy environment and poor air quality in schools is reflected through child-illness such as asthma and allergies, respiratory diseases (fever, flue, legionellosis and sinus infections), neurological problems (headache, difficulties in concentration, of productivity, uninteresting in learning, poorer test results) and increased absences and treatment costs [6], [8]. Some studies show that ill-advised energy conservation measures can reduce children's performance of schoolwork by as much as $30 \%$. This is a significant problem since students due to their age can be more susceptible to long-term health damage caused by poor IAQ in school buildings [4]. The ideal indoor environment is one with lots of outside, fresh air replacing the stale, contaminated air inside. The available research related to the improved student performance with increased classroom ventilation rates has shown that 8 out of 11 studies reported statistically significant improvements in at least some measures of student performance with increased ventilation rates or lower carbon dioxide concentrations [2].

Especially, the importance of adequate ventilation and IAQ came to the fore in a recent year, when humanity has been confronted with pandemic and COVID-19. Numerous studies today are doing research on how to reduce the spread of COVID virus in classrooms. For example, SARSCoV- 2 can also be transmitted through aerosols, particles smaller than droplets that remain in the air over time and distance, especially in a poorly ventilated room, with the potential to lead to super spreading events. Current evidence shows that it takes about $4 \mathrm{~min}$ for the number of small droplets in the air to be halved with no ventilation; whereas with only mechanical ventilation turned on in a room, the number of respiratory particles is halved in $1.4 \mathrm{~min}$. In a room that also has a door and window open, the number is halved after $30 \mathrm{~s}$; substantially faster than in poorly ventilated and unventilated rooms. An important approach to lowering the concentrations of indoor air pollutants or contaminants, including any viruses that may be in the air, is to increase ventilation. Increasing air flow by ventilation, whether by window and door opening or mechanical systems - which could mix outdoor air with indoor air or air filtration and cleaning devices, reduces the risk of infection by diluting concentrations of respiratory particles and removing them in the ambient air [17]. Educational buildings should be designed adhering to the principle of sustainability and taking into account that measurements for energy savings should not impact on conditions in the classrooms and negatively affect the productivity of students, as this would mean that the implementation of energy efficiency measures has a counterproductive effect [1].Simply said, energy declaration without declaration related to the inside environmental quality does not make sense [3].

\section{Recommended values of IAQ parameters}

Regulatory restrictions on $\mathrm{CO}_{2}$ concentration in buildings have been established to assess the indoor air (IAQ). Ventilation and continuous air renewal in the building should ensure that the introduced air should, as far as possible, be free from any impurity that may affect the health of users; occupants should not be exposed to uncomfortable draughts and it is recommended, where necessary, to provide a mechanical ventilation systems as an addition to natural ventilation, if it is not possible to ensure a sufficient number of air changes naturally with regard to climatic conditions and purpose of the room [1], [9]. 
The concentration limits for $\mathrm{CO}_{2}$ can be described according to European Standard EN 16 798-1: 2019 [16], corresponding to three indoor air quality categories (Table 1). EN 16 798-1: 2019 replaces EN 15251 and it focusses on parameters at category I, II, III level - sometimes also level IV (level I is best, III / IV is worst) for thermal environment, indoor air quality, lighting and acoustics [10]. Note that this guideline is not designed to limit the amount of $\mathrm{CO}_{2}$, but rather to indicate that a proper level of clean air (15-20 CFM/person) is being distributed in a classroom [2].

According to ASHRAE, the recommended $\mathrm{CO}_{2}$ level in buildings should be no more than 700 parts per million (ppm) above outdoor air. Since outdoor air is approximately $400 \mathrm{ppm}$, indoor $\mathrm{CO}_{2}$ levels should be no more than $1100 \mathrm{ppm}$. Building Bulletin 101, 2016, recommends for naturally ventilated educational buildings, that the $\mathrm{CO}_{2}$ concentration should be less than $1500 \mathrm{ppm}[9]$.

\begin{tabular}{|c|c|c|c|}
\hline & $1^{\text {st }}$ category & $2^{\text {nd }}$ category & $3^{\text {rd }}$ category \\
\hline $\begin{array}{c}\mathrm{CO}_{2} \text { concentration (above outdoor concentration) } \\
(\mathrm{ppm})\end{array}$ & 550 & 800 & 1350 \\
\hline $\begin{array}{c}\mathrm{CO}_{2} \text { concentration (absolute values; outdoor } \mathrm{CO}_{2} \\
\text { concentration } 480 \mathrm{ppm}) \\
(\mathrm{ppm})\end{array}$ & 1030 & 1280 & 1830 \\
\hline $\begin{array}{c}\text { Temperature (winter) } \\
\left({ }^{\circ} \mathrm{C}\right)\end{array}$ & $21-23$ & $20-24$ & $19-25$ \\
\hline $\begin{array}{l}\text { Temperature (summer) } \\
\left({ }^{\circ} \mathrm{C}\right)\end{array}$ & $23,5-25,5$ & $23-26$ & $22-27$ \\
\hline
\end{tabular}

Table 1. $\mathrm{CO}_{2}$ concentration and temperature in schools according to EN 16798-1: 2019 [16]

The microclimate in educational buildings needs to maintain a thermal balance between students, ensuring the thermal comfort of the environment, which would lead to increased attention and concentration during the learning period [11]. It can be achieved with air temperature, relative humidity and air flow, whose values at a specific level are called "comfort zone". Relative humidity is determined based on temperature values. ASHRAE in a separate document (ASHRAE Standard 62), recommends that the relative humidity should be maintained between $30 \%$ and $60 \%$ [12], and according to [13] relative humidity in educational buildings should be between $45-55 \%$.

Digital equipment for carbon dioxide measurement is a relatively economical and efficient way to determine carbon dioxide concentration as indicator of IAQ and efficiency of ventilation system and it can detect the problem before users are aware of it [14], [15]. With long-term carbon dioxide monitoring in combination with measurement of air temperature and relative humidity, building management can have better insight in supporting decision making about ventilation control and improving HVAC system, which can lead to greater energy savings, improved overall air quality and raising social awareness, necessary for successful achievement of high environmental standards [5].

\section{Aim and methodology of research}

In 2011, at the Faculty of Mechanical Engineering Sarajevo (MEF) was implemented a pilot project of energy efficiency, which included the rehabilitation of facade, through thermal insulation, replacement of old windows and upgrading the heating system with replacement of an existing boiler. In the first year after the implementation of energy efficiency measures, about $43 \%$ of annual energy savings were achieved. After one month of monitoring the average indoor air temperature in the building, an increase of temperature was recorded from $19{ }^{\circ} \mathrm{C}$ to $21{ }^{\circ} \mathrm{C}$. However, the Faculty did not have mechanical ventilation at all, except of split systems in some rooms and it mainly relied on the natural ventilation [2]. Due to the partial implemented measures of energy efficiency, not including thermal insulation of a flat roof and adequate system for ventilation and cooling, in the first years after the implementation of the project, it was noticeable that these measures had impact of on the users' thermal comfort in classrooms and offices and increased cooling needs during the warmer period of the year.

The paper analyses the measurement of IAQ parameters, i.e. $\mathrm{CO}_{2}$ concentration, temperature and relative humidity, in the classroom 201. This classroom was chosen because of the usable area, as one of the larger classrooms at the Faculty, frequency of the use and orientation. Classroom 201 (Figure 1) is located on the second floor of the Western building of the Mechanical Engineering Faculty. The dimensions of the room are 15,9 x 9,32 m, the classroom area is $148,62 \mathrm{~m}^{2}$, and the room volume is $498,84 \mathrm{~m}^{3}$. The orientation of window surfaces of the longer side is to the South and the shorter side to the East. The classroom has sun protection in the form of mechanized panels that can be moved and adjusted as needed. These is no mechanical ventilation, but it relies on natural ventilation. Heating at the MEF is automatically regulated throughout the whole week and starts at 06:00 a.m. 

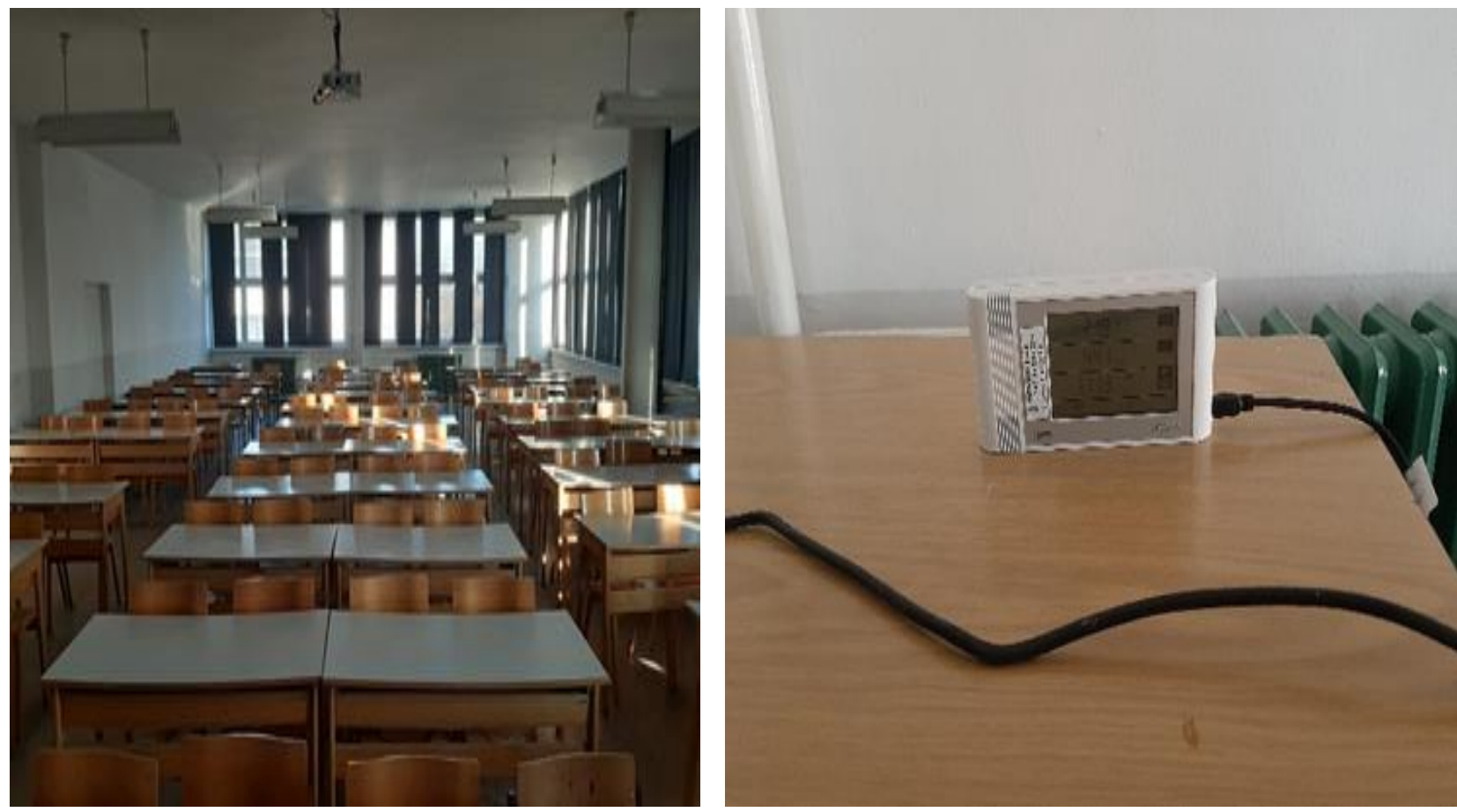

Fig. 1. Classroom 201 (left); location of data logger during measurement (right)

The device used to measure IAQ parameters is OPUS 20-TCO data logger, manufactured by Lufft (Figure 1). It is consisted of three internal sensors that measure values: air temperature (in the range from -20 to $+50{ }^{\circ} \mathrm{C}$ ), relative humidity (in the range 10-95\%) and $\mathrm{CO}_{2}$ concentration (0-5000 ppm). The device is placed $1 \mathrm{~m}$ above the floor, at the professor's desk, due to the distance from the entrance door to the classroom, but also duo to security reasons that may affect the accuracy of measurement data, because any movement and touching of data logger affects the reliability of the data. Air should circulate freely within the minimum zone, at a distance of $0,5 \mathrm{~m}$ around the sensor. The measurement range is set to measure every 10 seconds, and the value reading is displayed every 30 minutes.

\section{Analysis of measured IAQ parameters in the classroom 201}

The measurements were performed in the winter semester and consisted of two measurement periods. First measurement period lasted from $27^{\text {th }}$ November to $1^{\text {st }}$ December of 2019 , and second measurement period lasted from $1^{\text {st }}$ December to $6^{\text {th }}$ December of 2019. The heating season was chosen for the measurement because this period is characterized by a greater differences between indoor and outdoor temperatures, but also due to the user's behavior in terms of habits and awareness of the necessary frequent ventilation of the room. Usually during the winter period, due to the lower outside temperature values, windows are less open for ventilation because it affects the decrease of the internal temperature and creating discomfort for the users.

The number of students in the classroom 201 in one class ranged in average from 21 to 52, depending on the subject. According to the schedule, one hour of lectures lasts 45 minutes, while the break between classes lasts 15 minutes. During the measurement, the usual behavior of users in the classroom was monitored, i.e. the environment was not controlled. The schedule of classes was not $100 \%$ reliable, because there were deviations between the actual situation and the predicted schedule. Some classes were held based on an agreement between professor and students. In the following subsections, the measured values of IAQ parameters in the classroom 201 are analyzed.

\section{Results and discussion}

\subsection{First measurement period (27 $7^{\text {th }}$ November $-1^{\text {st }}$ December 2019)}

Figure 2 shows the measured values of IAQ parameters for the first measurement period in the classroom 201. 


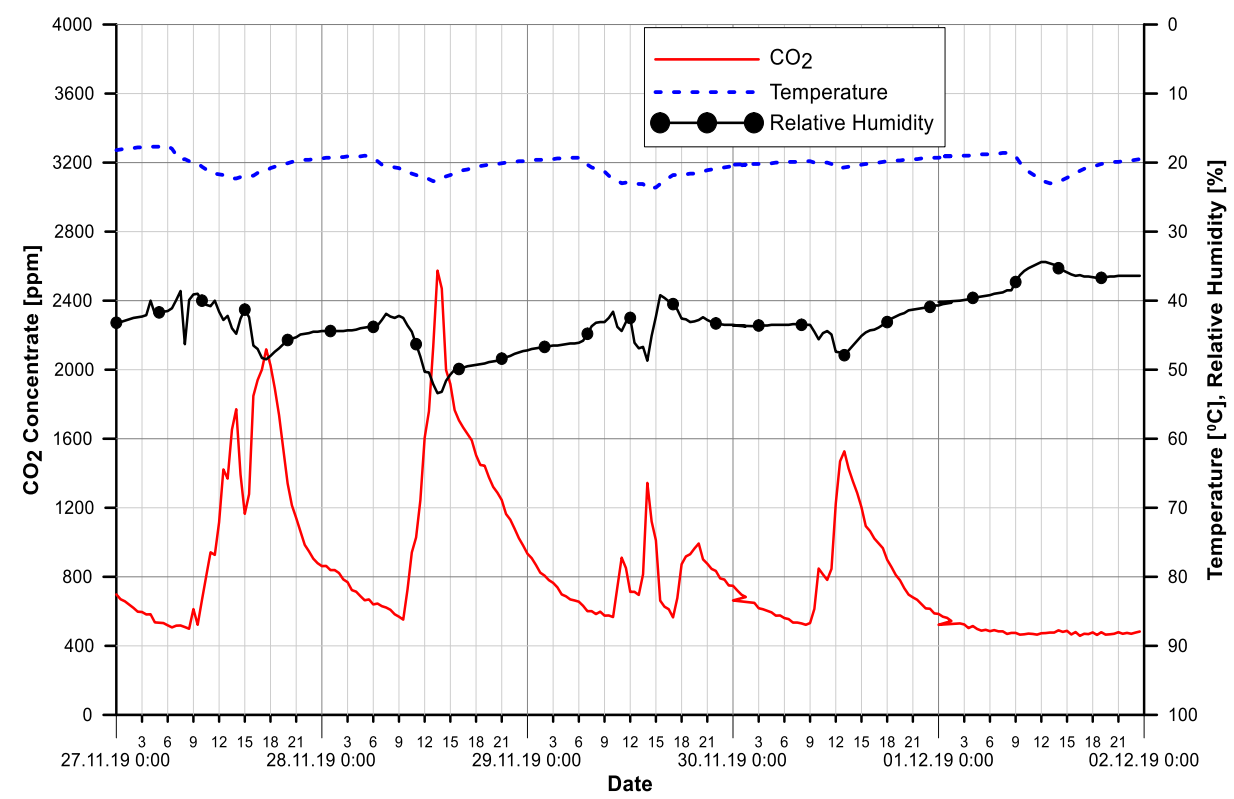

Fig. 2. Measured values of IAQ parameters for first measurement period in the classroom 201 (27 $7^{\text {th }}$ November- $1^{\text {st }}$ December 2019)

With the start of lecture on the first measurement day, at 9:15 a.m., $\mathrm{CO}_{2}$ concentration was low, $499 \mathrm{ppm}$. The lectures lasted according to the schedule from 9:15 a.m. to 15:00 p.m., and an additional lecture was held from 15:15 p.m. to 17:30 p.m. During the first lecture (9:15-11:15), which was attended by about 21 students, $\mathrm{CO}_{2}$ concentration increased from 499 ppm to $942 \mathrm{ppm}$, at the end of class.

During the second lecture (11:15-15:00) with about 51 students attended, $\mathrm{CO}_{2}$ concentration ranged from $927 \mathrm{ppm}$ at 11:15 a.m., to $1165 \mathrm{ppm}$ at 15:00 p.m. From the beginning of the lecture, there was a continuous increase in the concentration, with a peak value for that period, $1771 \mathrm{ppm}$ at 14:00 p.m. After 14:00 p.m., the value began to decline, indicating that class has finished earlier, and students left the classroom. At 15:15 p.m., the $\mathrm{CO}_{2}$ concentration starts to rise again from $1165 \mathrm{ppm}$ to $2118 \mathrm{ppm}$, measured at 17:30 p.m., which is the maximum concentration of $\mathrm{CO}_{2}$ for that day. It took about 2 hours and 30 minutes for the $\mathrm{CO}_{2}$ concentration to drop from the maximum measured value of that day, i.e. from 2118 ppm at 14:30 p.m. to 985 ppm at 22:00 p.m.

$\mathrm{CO}_{2}$ concentration decreased slightly during the breaks, which is shown in the example when at the beginning of the break at 11:00 the concentration was $942 \mathrm{ppm}$, and at 11:30 a.m. with the start of class, the measured concentration was $972 \mathrm{ppm}$. Usually, during the winter period, students rarely go out because the hallways are much colder than the classroom.

On Thursday, 28.11.2019, lectures lasted from 9:15 a.m. to 14:00 p.m., with about 50 students attended. Measured value of $\mathrm{CO}_{2}$ concentration before the lecture was $552 \mathrm{ppm}$, and after the first class it was 727 ppm, with the continues growth. Half an hour before the end of classes, the maximum value of $2574 \mathrm{ppm}$ for that day was measured, and after 14:00 p.m. it decreased to $2470 \mathrm{ppm}$. Average increase of $\mathrm{CO}_{2}$ concentration every half hour from the beginning of the lecture till the end at 14:00 p.m., was $253 \mathrm{ppm}$. The total increase of concentration at the end of classes compared to the beginning of the lecture was 2022 ppm. It took 9 hours for the $\mathrm{CO}_{2}$ value to drop below 1000 ppm, i.e. by 23:00 p.m. concentration had dropped by $1489 \mathrm{ppm}$ to $981 \mathrm{ppm}$.

Although scheduled lectures for Friday were supposed to be held in the morning, they were still held from 13:00 p.m. to 15:00 p.m. The average number of students present was 53. At the beginning of the lecture, the measured $\mathrm{CO}_{2}$ concentration was $695 \mathrm{ppm}$, while at the end of classes, the concentration was $1011 \mathrm{ppm}$, which is the maximum value for that day. On Saturday, the classroom was used for additional classes, in the period from 11:00 a.m. to 14:00 p.m., which can be seen on Figure 2 through increase in $\mathrm{CO}_{2}$ concentration. Concentration of $\mathrm{CO}_{2}$ in that period ranged from $728 \mathrm{ppm}$ at 11:00 a.m. to $1353 \mathrm{ppm}$ at 14:00 p.m. After the class, it took about 3 hours to $\mathrm{CO}_{2}$ concentration decrease below $1000 \mathrm{ppm}$. On Sunday, when it is non-working day, the concentration ranged from $458 \mathrm{ppm}$ to $585 \mathrm{ppm}$.

On Friday, the highest temperature during the classes was measured for the first measurement period of $23,8^{\circ} \mathrm{C}$, with a gradual decrease after the end of classes. The average temperature during classes was $21,9{ }^{\circ} \mathrm{C}$, with a minimum value of $20,5{ }^{\circ} \mathrm{C}$ and a maximal $23,5^{\circ} \mathrm{C}$. During the weekend, an increase of air temperature was observed with the heating turned on, when temperature rose from $18,8{ }^{\circ} \mathrm{C}$ at 06:00 a.m. to $22,8{ }^{\circ} \mathrm{C}$ at 14:00 p.m. After 14:00 p.m., when the heating was switched off, the temperature values gradually decreased.

Average humidity during classes was around $45 \%$, with a minimum of $43 \%$ and a maximum of $53,4 \%$. The highest relative humidity of $54 \%$ for the first measurement period, was measured on Thursday at the time when the highest $\mathrm{CO}_{2}$ concentration of $2574 \mathrm{ppm}$ was measured. On the other days, the highest values of relative humidity were measured at the time when the highest concentration of $\mathrm{CO}_{2}$ was measured. 


\subsection{Second measurement period ( $2^{\text {nd }}$ December $-6^{\text {th }}$ December 2019)}

Figure 3 shows the measured values of IAQ parameters for the second measurement period in the classroom 201. On Monday, 02.12.2019, lecture started at 11:00 a.m. with a total number of 57 of present students. $\mathrm{CO}_{2}$ concentration measured at the beginning of lecture was $595 \mathrm{ppm}$, and at 13:30 p.m., it reached maximum weekly value of 3543 ppm, which is almost three times higher than recommended standard. In half an hour, by about 14:00 p.m., the value decreased by 290 ppm, and by 15:00 p.m. total $\mathrm{CO}_{2}$ drop was by 2495 ppm, i.e. the value dropped to 1048 ppm. After 15:00 p.m., $\mathrm{CO}_{2}$ values were below $1000 \mathrm{ppm}$.

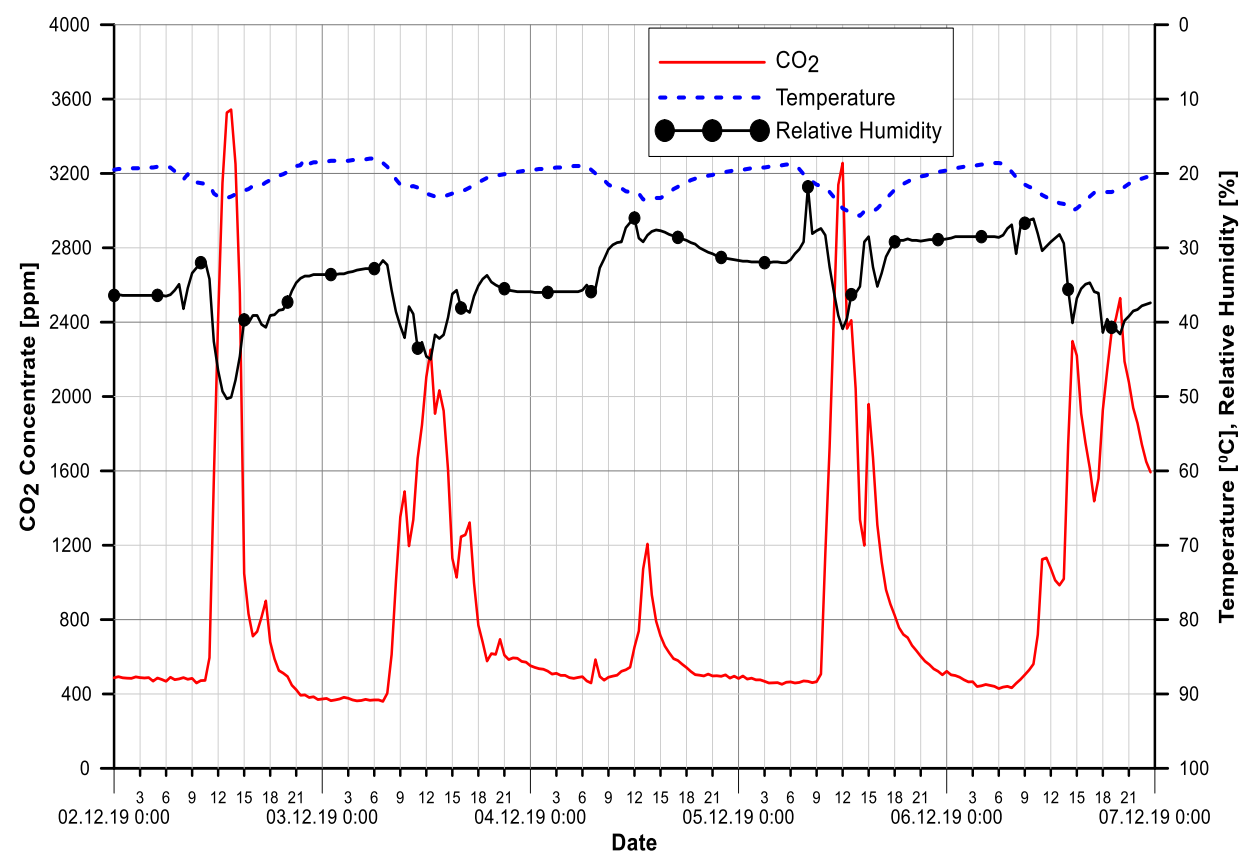

Fig. 3. Measured values of IAQ parameters for first measurement period in the classroom $201\left(2^{\text {nd }}\right.$ December- $6^{\text {th }}$ December 2019)

On Tuesday, $\mathrm{CO}_{2}$ concentration during the first lecture (8:15-14:00) ranged from 612- 2252 ppm, and during the second held lecture (15:00-17:00), it ranged from 1027-1322 ppm. During the break between these two classes, the value dropped by 793 ppm, i.e. from 1923 to 1130 ppm. After the end of classes at 17:00 p.m., it took about 30 minutes for the $\mathrm{CO}_{2}$ value to drop by $325 \mathrm{ppm}$ to below $1000 \mathrm{ppm}$ (997 ppm). On Wednesday, average $\mathrm{CO}_{2}$ concentration ranged from 652-1 207 ppm.

Second maximum $\mathrm{CO}_{2}$ value for the second measurement period, was measured on Thursday, 05.12.2019. According to the schedule for the classroom 201, lecture was held in the period from 9:15 a.m. to 14:00 p.m., attended by 50 students. $\mathrm{CO}_{2}$ concentration measured at 9:00 a.m. was $466 \mathrm{ppm}$. At 12:00 a.m., it reached a value of $3256 \mathrm{ppm}$, which is also the maximum daily value of $\mathrm{CO}_{2}$. The lecture lasted until 13:00 p.m. and at the end of lectures, measured $\mathrm{CO}_{2}$ concentration has reached the value of $2410 \mathrm{ppm}$. It took 4 hours from maximum measured value, i.e. after 17:00 p.m. for the concentration to decrease by about 1449 ppm, to a value below 1000 ppm (961 ppm).

On Friday, a characteristic increase in $\mathrm{CO}_{2}$ concentration was measured throughout the day, as shown on Figure 3. The first increase of concentration was observed from 10:00 a.m., with the value of $561 \mathrm{ppm}$, and within the hour, the concentration doubled, to 1124 ppm. From 12:00 a.m., the value decreases from 1021 to 985 ppm at 13:00 p.m. From 13:00 p.m., the value doubled again, i.e. at 14:30 p.m., the value of 2298 ppm was measured. By 18:30 p.m., CO concentration decreased by 370 ppm to 1928 ppm, and after 18:30 p.m., there was again an increase of 601 ppm. At 20:00 p.m. the value of $2529 \mathrm{ppm}$ was measured, and at 23:30 p.m. the concentration of $\mathrm{CO}_{2}$ was 1593 ppm, which is a higher value for that period of time. These values are an indicator of how important is to ventilate the space after the end of classes because higher values will continue to be present until the beginning of the new working week.

The average temperature during classes was $23{ }^{\circ} \mathrm{C}$, with a minimum of $19,8{ }^{\circ} \mathrm{C}$ and a maximal $25{ }^{\circ} \mathrm{C}$. Temperature values followed the increase of $\mathrm{CO}_{2}$ concentration during the classes. After the end of classes, with the decrease of $\mathrm{CO}_{2}$ concentrations, the room temperature also decreased. On Thursday when the maximum $\mathrm{CO}_{2}$ concentration of $3256 \mathrm{ppm}$ was measured, the air temperature was $24,7^{\circ} \mathrm{C}$ and it continued to rise by one degree till the end of class, after which there was decrease along with the decrease of $\mathrm{CO}_{2}$. Average humidity during classes was around $36 \%$, with a minimum of $26 \%$ and a maximum of $50,3 \%$, which is the highest value measured on Monday, at the time when the highest $\mathrm{CO}_{2}$ concentration of $3251 \mathrm{ppm}$ was measured during the second measurement period.

Table 2 shows the overall measured values of IAQ parameters during the whole day and during the lectures, for the first and second measurement period in the classroom 201. 


\begin{tabular}{|c|c|c|c|c|}
\hline Measured period & \multicolumn{2}{|c|}{ I measurement period } & \multicolumn{2}{|c|}{ II measurement period } \\
\hline Parameters & All day & Lectures & All day & Lectures \\
\hline Maximum $\mathrm{CO}_{2}$ concentration (ppm) & 2574 & 2574 & 3543 & 3543 \\
\hline Average $\mathrm{CO}_{2}$ concentration (ppm) & 853 & 1106 & 891 & 1596 \\
\hline Average air temperature $\left({ }^{\circ} \mathrm{C}\right)$ & 20 & 21,5 & 20,9 & 23 \\
\hline $\begin{array}{c}\text { Average } \\
\text { relative humidity } \\
(\%)\end{array}$ & 43 & 44,1 & 33,9 & 35,8 \\
\hline
\end{tabular}

Table 2. Measured IAQ values for the first and second measurement period in the classroom 201

Based on the measurement results, it can be concluded that the maximum values of $\mathrm{CO}_{2}$ exceed 2-3 time more than the recommended values according to the standard EN 16798-1:2019. The mean $\mathrm{CO}_{2}$ concentration during the day was in the recommended values, while the mean value during the lectures exceeded the recommended value by $36 \%$. Temperature values during the first measurement period, for the whole day and during the lectures were in the recommended values according to the EN 13790, while during the second measurement period, a slightly higher value was measured by about $2{ }^{\circ} \mathrm{C}$, compared to the recommended $21^{\circ} \mathrm{C}$. The mean relative humidity was in the recommended range. On Thursday of the first measurement period, it took about $10 \mathrm{~h}$ to decrease the maximum $\mathrm{CO}_{2}$ concentration of 2 574 ppm, measured at 13:30 p.m., to 981 ppm at 23:30 p.m. While in the second measurement period, on Monday it took about 2 hours for the maximum value of 3543 ppm, measured at 13:30 p.m., to decrease to $831 \mathrm{ppm}$ at 15:30 p.m. It is possible to conclude based on the shorter time required to decrease the $\mathrm{CO}_{2}$ value on Monday of the second measurement period, that the classroom was ventilated by opening the windows after the end of class, thus enabling a faster decrease of $\mathrm{CO}_{2}$ concentration, which again emphasize that after the end of classes, it is very important to ventilate the classroom, to change indoor stale air and with introduced fresh air reduce the concentration of carbon dioxide, lower the temperature, and humidify the existing air. By ventilation of the room, the rate of decrease of $\mathrm{CO}_{2}$ concentration increased almost by 3 times. Measured high values of $\mathrm{CO}_{2}$ concentration during the lectures indicate that the high values are not only caused by airtightness of the building, but also there is insufficient ventilation of the spaces and the user's attitude towards this issue.

\section{Conclusion}

The paper analyzed the measurements of IAQ parameters in the classroom 201, at Faculty of Mechanical Engineering in Sarajevo, to estimate ventilation efficiency from the aspect of measured $\mathrm{CO}_{2}$ concentration in the chosen classroom. In introduction part, the importance and impact of the indoor environmental parameters on the health and well-being of users are described, as well as the recommended values according to the different standards. Standard EN 16798-1:2019, that replaced EN 15251, was used to assess the air quality in the classroom. Experimental research was performed in the classroom 201, where the parameters of IAQ $\left(\mathrm{CO}_{2}\right.$ concentration, temperature, and relative humidity) were measured. The results of measurement showed the presence of higher $\mathrm{CO}_{2}$ concentrations during the heating season, where individual values exceeded the recommended value by up to two or three times. Since the most common way of expressing adequate ventilation rate is through $\mathrm{CO}_{2}$ concentration, high measured $\mathrm{CO}_{2}$ concentration indicates low or inefficient ventilation, which is often the case in the buildings that are naturally ventilated. Some of the factors that affect the higher values of $\mathrm{CO}_{2}$ are airtightness of the buildings, which is the case at the Faculty of Mechanical Engineering Sarajevo where energy efficiency measures have been implemented, but without adequate ventilation system. In addition, the higher concentration is also affected by the room spatial characteristics, the class schedule, number of users, and the frequency of ventilation of the room. The choice of the most appropriate ventilation system for improvement of IAQ in the classrooms depends on many factors, and very often there are spatial limitations or financial restrictions, especially if it is a case of a State institutions and limited budget. Accordingly, it is recommended to apply, as much as possible, simple measures as passive ventilation (night and early morning), more frequent ventilation of the classroom before, during and after the end of class, installation of $\mathrm{CO}_{2}$ concentration sensor as recommendation for schools because it indicates high concentration and the need for ventilation. If energy efficiency measures do not include the measure of providing adequate ventilation system, users should partly take an obligation to maintain a quality indoor environment through more frequent ventilation. This is where the importance of user's awareness about the indoor air quality and their role in achieving and maintaining it comes to the fore, as the factor that should not be neglected. This model of behavior should not only be applied to, in this case, educational institutions, but also to the wider community and households.

After analyzing the research of the impact of implemented energy efficiency project on the building of Faculty, through insulation of the building but without adequate ventilation system, future research plans will be concentrated on two areas. First one refers to the measurement of IAQ parameters in the building of primary school, since many research have shown that younger children are more susceptible to the influence of poor indoor air. 
The frequency of ventilation in classes with younger children compared to students, depends on the teacher's attitude, and because children are not capable and aware to such an extent that it is necessary to ventilate the space. Two primary schools will be selected, a school building which is thermal insulated and a school that has not been renovated since the construction period. The aim is to compare measurement results in dependence of the structural characteristics of the building. The second area relates to the analysis of IAQ measurements in the classroom when air-purifier is being used. Since the air in Sarajevo is more polluted every year, most institutions use indoor air purifiers. The IAQ parameters will be measured and analyzed for the period when the air purifier is not used in the classroom and for the period when it is used, in order to compare measurement IAQ results.

\section{References}

[1] Zečević, N. (2019). Development of a model for determining the optimal combination of energy efficiency measures and renewable energy technologies on the buildings of higher education institutions in Bosnia and Herzegovina, Ph.D. Dissertation, University of Sarajevo, Faculty of Mechanical Engineering Sarajevo, Bosnia and Herzegovina.

[2] CO2 meter. Indoor Air Quality in Classrooms and COVID19. (2021). Available from: http:// www.co2meter.com/blogs/news/7334762-indoor-air-quality-in-the-classroom, Accessed: 2021-06-10.

[3] Olesen, W.B. (2012). Revision of EN 15251: Indoor Environmental criteria, International Centre for Indoor Environment and Energy, REHVA Journal, Department of Civil Engineering, Technical University of Denmark. Available from: https:/www.rehva.eu/rehva-journal/chapter/revision-of-en-15251-indoor-environmental-criteria, Accessed: 2021-06-15.

[4] Zemitis, J., Bogdanovics, R, Bogdanovica, S. (2021). The study od CO2 concentration in the classroom during the COVID-19 safety measures, E3S Web of Conferences 246, 01004, Cold Climate HVAC \& Energy 2021. Available from: https://www.e3s- conferences.org/articles/e3sconf/pdf/2021/22/e3sconf_hvac2021_01004.pdf, Accessed: 2021-06-24, DOI: 10.1051/e3sconf/202124601004.

[5] Zecevic, N., Husika, A., Dzaferovic, E. (2018). Impact of energy efficiency measures on indoor air quality in building of Mechanical Engineering Faculty Sarajevo, Proceedings of the 29th DAAAM International Symposium, pp. 0197-0201, B. Katalinic (Ed.), Published by DAAAM International, ISBN 978-3-902734-20-4, ISSN 17269679, Vienna, Austria. DOI: 10.2507/29th.daaam.proceedings.028

[6] Mendell, M.J., Heath, G.A. (2005). Do Indoor pollutants and thermal conditions in schools influence student performance? A critical review of the literature, Indoor Air 2005, pp. 27-52. DOI:10.1111/j.16000668.2004.00320.x

[7] Shendell, D.G., Pril, R., Fisk, R., Apte, M.G, Blake, D., Faulkner, D. (2004). Association between classroom CO2 concentrations and student attendance, Indoor Air 2004; 14 (5): 333-41.

[8] Kats, G. (2006). Greening America's Schools: Costs and benefits, A Capital E. Reports, Available from: https://www.usgbc.org/resources/greening-america039s-schools-costs-and-benefits, Accessed: 2021-06-24.

[9] Building Bulletin 101. (2016). Guidelines on ventilation, thermal comfort and indoor air quality in schools, Department for education. Information Policy Team, The National Archives, Kew, London, TW9 4DU. Available from:https://consult.education.gov.uk/capital/bb101-school-design-iaq-comfort-andventilation/supporting_documents/DfE\%20Ventilation\%20guide\%20consultation\%20draft\%2029\%2006\%202016 .pdf, Accessed: 2021-06-26.

[10] Bogdanovica, S., Zemitis, J., Bogdanovics, R. (2020). Effects of CO2 concentration on children's well-being during the process of learning, Energies 2020, 13, 6099, Available from: https://www.mdpi.com/19961073/13/22/6099/pdf, Accessed: 2021-06-28.

[11] United States Environmental Protection Agency (EPA). (2020). Why Indoor Air Quality is important to Schools. Available from: https:/www.epa.gov/iaq-schools/why-indoor-air-quality-important-schools,Accessed: 2021-06-28.

[12] School Service Health and Safety. (2010). Code of practice and guidelines for schools, nurseries and children centres on thermal comfort, Ealing Education Service.

[13] Auf-Franić, H., Oluić, V., Žarnić, T., Bertina, M., Korlaet, L., Rister, V., Roth-Čerina, M. (2003). Osnovne škole programiranje, planiranje i projektovanje, Arhitektonski fakultet Sveučilišta u Zagrebu.

[14] Lowitz, G. (2015). Managing Carbon-Dioxide Risk: What You Should Know, ONSET HOBO, Available from: https://www.microdaq.com/downloads/dl/file/id/917/product/3090/managing_carbon_dioxide_risk.pdf, Accessed: 2021-07-20.

[15] AirTest, (n.d). CO2 Control in School Classrooms. Available from: http://www.airtest.com /support/reference/CO2\&SchoolClassrooms.pdf, Accessed: 2021-07-05.

[16] EN 16 798-1:2019. (2019). Energy performance of buildings- Ventilation for buildings- Part 1: Indoor environmental input parameters for design and addressing indoor air quality, thermal environment, lighting and acoustics- Module M1-6.

[17] Asanati, K., Voden, L., Majeed, A. (2021). Healthier schools during the COVID-19 pandemic: ventilation, testing and vaccination, Journal of the Royal Society of Medicine; 2021, Vol. 114 (4), pp.160-163. DOI:10.1177/0141076821992449 